1 Ghali JK, Cooper R, Ford E. Trends in hospitalization rates for heart failure in the United States, 1973-1986. Evidence for increasing population prevalence. Arch Intern Med 1990;150:769-73.

2 McMurray J, McDonagh T, Morrison CE, Dargie HJ. Trends in hospitalization for heart failure in Scotland 1980-1990. Eur Heart J 1993;14:115862.

3 Eriksson H. Heart failure: a growing public health problem.J Intern Med 1995;237:135-41.

4 Bonneux L, Barendregt JJ, Meeter K, Bonsel GJ, van der Maas PJ. Estimating clinical morbidity due to ischemic heart disease and congestive heart failure: the future rise of heart failure. Am J Public Health 1994;84:20-8.

5 McMurray J, Hart W. The economic impact of heart failure on the UK National Health Service. Eur Heart J 1993;14(suppl):133.

6 CONSENSUS Trial Study Group. Effects of enalapril on mortality in severe congestive heart failure. Results of the cooperative north Scandinavian enalapril survival study. N Engl J Med 1987;316:1429-35.

7 The SOLVD Investigators. The effects of enalapril on survival in patients with reduced left ventricular ejection fractions and congestive heart failure. N Engl J Med 1991;325:293-302.

8 Cohn JN, Archibald DG, Ziesche S, Franciosa JA, Harston WE, Tristani $\mathrm{FE}$, et al. Effect of vasodilator therapy on mortality in chronic congestive heart failure. Results of a veterans affairs administration cooperative study. N Engl J Med 1986;314:1547-52

9 Cohn JN, Johnson G, Ziesche S, Cobb F, Francis G, Tristani F, et al. A comparison of enalapril with hydralazine-isosorbide dinitrate in the treatment of chronic congestive heart failure. $N$ Engl $J \mathrm{Med}$ 1991;325:303-10.

10 Garg R, Yusuf S. Overview of randomized trials of angiotensinconverting enzyme inhibitors on mortality and morbidity in patients with heart failure. Collaborative group on ACE inhibitor trials. JAMA heart failure. Co

11 The SOLVD Investigators. Effect of enalapril on mortality and the development of heart failure in asymptomatic patients with reduced left ventricular ejection fractions. N Engl J Med 1992;327:685-91.

12 McKinnon ME, McKee CM. Heart failure: the Cinderella of cardiology. Public Health 1996:110:351-5

13 McKee PA, Castelli WP, McNamara PM, Kannel WB. The natural history of congestive cardiac failure: the Framingham study. $N$ Engl J Med 1971;285:1441-6
14 Schocken DD, Arrieta MI, Leaverton PE, Ross EA. Prevalence and mortality rate of congestive heart failure in the United States. J Am Coll Cardiol 1992;20:301-6.

15 McDonagh TA, Morrison CE, Lawrence A, Ford I, Tunstall-Pedoe H, McMurray JJV. Symptomatic and asymptomatic left-ventricular dysfunction in an urban population. Lancet 1997;350:829-33.

16 Schiller NB, Shah PM, Crawford M, DeMaria A, Devereux R, Feigenbaum $\mathrm{H}$, et al. Recommendations for quantitation of the left ventricle by two-dimensional echocardiography. American Society of Echocardiography Committee on Standards, Subcommittee on Quantitation of Two-Dimensional Echocardiograms. J Am Soc Echocardiography 1989;2:358-67.

17 Stata Statistical Software: Release 4.0. College Station, Tx: Stata Corporation, 1995.

18 Mosterd A, de Bruijne MC, Hoes AW, Deckers JW, Hofman A, Grobbee DE. Usefulness of echocardiography in detecting left ventricular dysfunction in population-based studies (the Rotterdam Study). Am J Cardiol 1997;79:103-4.

19 Parameshwar J, Shackell MM, Richardson A, Poole-Wilson PA, Sutton GC. Prevalence of heart failure in three general practices in north west London. Br J Gen Prac 1992;42:287-9.

20 Mair FS, Crowley TS, Bundred PE. Prevalence, aetiology and management of heart failure in general practice. $\mathrm{Br} J$ Gen Prac 1996;46:77-9.

21 Remes J, Miettinen H, Reunanen A, Pyorala K. Validity of clinical diagnosis of heart failure in primary health care. Eur Heart J 1991;12:315-21.

22 Amico AF, Lichtenberg GS, Reisner SA, Stone CK, Schwartz RG, Meltzer RS. Superiority of visual versus computerized echocardiographic estimation of radionuclide left ventricular ejection fraction. Am Heart $J$ 1989;118:1259-65.

23 Badgett RG, Lucey CR, Mulrow CD. Can the clinical examination diagnose left-sided heart failure in adults? JAMA 1997;277:1712-9.

24 Gillespie ND, McNeill G, Pringle T, Ogston S, Struthers AD, Pringle SD. Cross sectional study of contribution of clinical assessment and simple cardiac investigations to diagnosis of left ventricular systolic dysfunction in patients admitted with acute dyspnoea. BMJ 1997;314:936-40.

(Accepted 30 October 1998)

\title{
Patients' perceptions of medical explanations for somatisation disorders: qualitative analysis
}

\author{
Peter Salmon, Sarah Peters, Ian Stanley
}

\section{Department of \\ Clinical Psychology, \\ University of \\ Liverpool, \\ Liverpool L69 3GB \\ Peter Salmon, \\ professor \\ Sarah Peters, \\ research assistant \\ Department of \\ Primary Care, \\ University of \\ Liverpool, \\ Liverpool L69 3GB \\ Ian Stanley, \\ emeritus professor \\ Correspondence to: Professor Stanley}

BMJ 1999;318:372-6

\begin{abstract}
Objectives To describe, from the perspective of patients, distinguishing features of doctors' attempts to explain the symptoms of somatisation disorders. Design Qualitative analysis of verbatim records of interviews in which patients recounted doctors' explanations of their symptoms.

Setting Patients with persistent somatising symptoms referred from general practices in Liverpool and $\mathrm{St}$ Helens and Knowsley were interviewed before entry into a treatment programme.

Subjects 228 of 324 patients referred were interviewed. Initial interviews were used to develop the process and technique, and the final analysis was based on a subsample of 68 records, randomly chosen from the transcripts of 188 subjects who were interviewed subsequently.

Results Doctors' explanations were often at odds with the patients' own thinking. Analysis showed that medical explanations could be grouped into one of three categories, defined by the patients' perceptions. Most explanations were experienced as rejecting the reality of the symptoms. An intermediate category comprised explanations that were viewed as colluding, in which the doctor acquiesced with the patients' own biomedical theories. However, a few explanations
\end{abstract}

were perceived by patients as tangible, exculpating, and involving. These explanations were experienced by patients as satisfying and empowering.

Conclusions Patients with somatisation disorders feel satisfied and empowered by medical explanations that are tangible, exculpating, and involving. Empowering explanations could improve these patients' wellbeing and help to reduce the high demands they make on health services.

\section{Introduction}

The nomenclature of disease has been developed to facilitate communication between doctors and other healthcare professionals. It is not designed to provide explanations for patients, and may occasionally be used to obscure their understanding. ${ }^{1}$ Recent emphasis on doctors' communication skills reflects not only mounting pressure from patients who want information so that they can participate in their own care $^{2}$ but also the profession's wish to uphold its traditional responsibility of translating its language and thinking into terms that can be understood by lay people. ${ }^{34}$

Lay beliefs about illness form a parallel but much less well recognised explanatory system reflecting cultural, social, and political influences-for example, from the media or the activities of pressure groups. ${ }^{56}$ 
The existence of this parallel understanding implies an additional task of consultation: the need to reconcile medical and lay explanatory models of illness. The challenge that this presents is highlighted by patients who persistently seek help for physical symptoms, but in whom there is no evidence of physical abnormalitythat is, patients with somatising disorders. ${ }^{78}$

Although these patients seek explanations from doctors, they may already have a set of beliefs about the physical origins of their symptoms. Their doctors, however, may be aware of psychological factors and may realise that a physical cause is unlikely. For the doctor, therefore, the dilemma is how to respond in ways that help to reconcile differing, and potentially conflicting, explanatory models. Previous studies suggest that despite awareness of relevant social and psychological factors, doctors frequently acquiesce when these patients express their belief in a physical cause for their symptoms. ${ }^{910}$ By arranging investigations, specialist referral, and symptomatic treatment, doctors reinforce discrepancies rather than reconciling different explanations.

Although the beliefs that patients with somatising disorders have about their symptoms are well documented, we do lack accounts of their reactions to the explanations given by their doctors. ${ }^{11-13}$ In this study, we recruited patients with persistent physical symptoms in whom investigations had failed to show any abnormality; this ensured that they had considerable experience of having their symptoms explained by doctors. Qualitative methods were used to collect and analyse the medical explanations given to these patients.

\section{Methods}

\section{Subjects}

All 441 general practitioners in Liverpool and St Helens and Knowsley were asked to refer patients with physical symptoms that had persisted for at least 12 months and were unexplained by hospital investigations for recruitment into a controlled study of aerobic exercise training. Approval had been given by all local ethical committees.

Altogether 228 of the 324 subjects referred participated. Fifteen were excluded from the study because of hypertension, ischaemic heart disease, or psychosis and 81 refused to participate. Subjects completed the hospital anxiety and depression scale ${ }^{14}$ and were interviewed by one of the authors (SP). Access to the general practice records of subjects provided data on contacts with health services and the range of symptoms noted in the 6 months before recruitment.

\section{Interviews}

The interview procedure was piloted on the first 40 subjects in order to refine the procedure and methods. Patients dictated the pace and sequencing of interviews. The non-medical interviewer avoided closed questions and encouraged patients to talk in their own ways about their symptoms and the doctors' explanations of them. Any relevant statement was noted, verbatim, by the interviewer.

\section{Analysis of interview transcripts}

Our analysis drew on the 188 transcripts available after the interview procedure had been finalised. Analysis was inductive and followed established conventions for ensuring that the process was grounded in the data rather than reflecting pre-existing ideas. ${ }^{15}{ }^{16}$ The interviewer and one other author drew up preliminary categories and themes based on careful reading and re-reading of 30 records chosen at random. The categories identified were based on common accounts from several patients; isolated comments from individual patients were insufficient. The analysis was then tested and developed in two ways. Firstly, these authors applied it to a further 20 records and modified it accordingly. Secondly, the remaining author read all 50 records before discussion between all authors. Finally, 18 further records were read and discussed. The analysis was finalised when no further modifications emerged and all relevant text could be categorised.

The importance of cross referral between the data and the developing analysis, and the use of different authors in different roles, is widely recognised. ${ }^{17}{ }^{18} \mathrm{In}$ addition, key criteria of validity for our purposes included coherence of the final analysis ${ }^{18}$ and so called catalytic validity, ${ }^{19}$ which is essentially the utility of the analysis in providing outcomes that can be tested.

\section{Results}

\section{Characteristics of subjects}

The mean (SD) age of the subjects was 44.5 (12.1) years, and $52 \%$ were women. Data from the general practice records were available for 54 subjects (79\%); for eight patients the records were unavailable and for six consent was withheld. Subjects generally had several symptoms (mode 3, median 4, range 0-10). Table 1 summarises the major groups of recorded symptoms.

Scores on the hospital anxiety and depression scales were raised $(>8)$ in most subjects. Documented, age related use of healthcare services in the 6 months before the study was well above that expected for contacts with general practitioners (mode 8, median 9, range 0-27) and hospital attendances (mode and median 2 , range $0-12) .^{20}$

\section{Patients' accounts of explanations}

An analysis of patients' perceptions of the causes of their illness has been reported elsewhere. ${ }^{21}$ The present paper is concerned solely with patients' accounts of their doctors' explanations of symptoms. In our final analysis these explanations were grouped into just three types: rejection (denying the reality of symptoms); collusion (sanctioning the patient's beliefs by acquiescence); and empowerment (explanations that were assimilated and were empowering). The box summarises the features and implications of the three types of explanation, and each type is illustrated by extracts from interview transcripts (below).

\section{Rejection}

The central element of patients' experience of these explanations was typically doctors' denial of their 
Table 1 Symptoms occurring in more than $5 \%$ of the 54 subjects for whom general practitioners' records were available

\begin{tabular}{ll} 
Symptom & $\begin{array}{c}\text { No }(\%) \text { of patients } \\
\text { with symptom }\end{array}$ \\
\hline Fatigue & $14(26)$ \\
\hline Back pain & $13(24)$ \\
\hline Neck pain & $13(24)$ \\
\hline Depression & $13(24)$ \\
\hline Anxiety & $9(16)$ \\
\hline Non-specific pain & $9(16)$ \\
\hline Chest pain & $8(14)$ \\
\hline Sleep disturbance & $7(13)$ \\
\hline Rash & $7(13)$ \\
\hline Sore throat & $7(13)$ \\
\hline Urinary tract infection & $7(13)$ \\
\hline Wheezing or breathlessness & $7(13)$ \\
\hline Abdominal pain & $6(11)$ \\
\hline Cough or chest infection & $6(11)$ \\
\hline Headache & $6(11)$ \\
\hline Arm pain & $6(11)$ \\
\hline Superficial infection & $6(11)$ \\
\hline Upper respiratory tract infection & $6(11)$ \\
\hline Weakness/malaise & $6(11)$ \\
\hline Non-specific bowel or rectal symptoms & $5(9)$ \\
\hline Vomiting or nausea & $5(9)$ \\
\hline Vaginal discharge & $4(7)$ \\
\hline Dizziness & $4(7)$ \\
\hline Irritable bowel & $3(6)$ \\
\hline Leg pain & $3(6)$ \\
\hline Menstrual disorders & $3(6)$ \\
\hline Post-viral symptoms & $3(6)$ \\
\hline Swelling & $3(6)$ \\
\hline
\end{tabular}

symptoms, most clearly where negative test results had been taken to indicate that there was nothing wrong.

They don't know, but they can't tell you that. So they say it's nothing.

I feel like something's not right and I don't know who else to go to if the doctor says "Go away." He said to me last time, "What else do you expect me to do?" Well, I don't know, keep trying I suppose.

Some explanations of this type were perceived as implying culpability or weakness:

So the doctor doesn't think anything's wrong. He keeps saying I'm just unfit. Isn't that stupid?

However, a diagnosis of anxiety or depression was generally seen in this way too, with the implication that symptoms were unjustified or imaginary.

Had all the tests done. Doctor says everything is fine. She says it's the anxiety and depression. No, can't see it myself. I mean, I do get tired and depressed like, but no more than anyone else. I don't know what it is, it's not what she thinks it is anyway. It's not bloody psychological. I'm not off my trolley. She thinks it's all in the mind.

These explanations were associated with disappointment that the doctor had not fulfilled expectations and was not, therefore, to be trusted with future symptoms.

I don't tell her now, I think she'll just laugh.

I'll only see him now if it's an emergency, like the kids or something.

\section{Collusion}

Collusion-simply sanctioning the patient's beliefs about their symptoms-refers to explanations that were described as originating with the patient rather than the doctor.

I plodded on wondering why I still felt terrible. Then, in the library, I just picked up this book by chance, book on ME or whatever. Went back to see Dr B ... and said "What about this, do you think this is it?" He said 'Oh yeah, I was thinking that myself.' He decided I had it. So it went from there.

Although the explanations were accepted by patients, this was at the expense of confidence in their doctor's openness.

I made myself go to the doctor about it, and I said "Have I got agoraphobia?" He said "Yes." I thought, "Well why couldn't you have told me?"

Alternatively, such an explanation was interpreted as reluctance on the part of the doctor to involve the patient in managing his or her own problem.

I seen a clip on TV, and thought "That's exactly what I feel." ... I said about ME. "Why didn't you tell me about it?" She said "I don't like to give out self help info, leaflets on self help stuff." They don't want you to help yourself.

\section{Empowerment}

Although uncommon, this set of accounts was distinctive in that patients had accepted explanations that attributed symptoms in ways which removed any sense of blame and provided them with opportunities to manage problems themselves.

I have clinical depression. The doctor explained it to me quite well, actually. It's between the neurones; in these synapses something goes awry. And that happens in clinical depression; an imbalance, exactly.

The following explanation enabled the patient to connect physical symptoms to depression:

\section{Types of explanation for patients' symptoms given by doctors}

Rejection

- Denies reality of symptoms

- Implies imaginary disorder or stigmatising psychological problem

Implications:

- Unresolved explanatory conflict

- Doctor distrusted with future symptoms

Collusion

- Acquiescence by doctor to explanation offered by patient

Implications:

- Questioning of doctor's openness and competence

Empowerment

Provides:

- Tangible mechanism

- Exculpation

- Opportunity for self management

Implications:

- Legitimises patient's suffering

- Patient understands and "owns" the explanation

- Removes blame from patient

- Allies doctor and patient 
Everything that hurts, I know that it's because of the brain cells not quite working.

Moreover, explanations of this type provided the basis for self management of the problem.

So I do feel fatigue, do get tired because I'm not getting the sleep at night. I wake up and think, oh now I'm awake, I have to try to be positive.

I'm on antidepressants. Not for depression, I'm happy with my life. It's to get your bad days up to a level with your good days. The doctor explained this. So when you have bad days, they're not so bad. Then you can work on the good days and do more.

Empowering explanations were not limited to psychological processes. They provided a link between psychological and physical effects:

He explained about tensing myself up so the neck kept hurting.

Finally, one patient articulated the benefits of empowerment explicitly:

I felt a sense of wellbeing, doing something positive to aid my own recovery.

\section{Discussion}

There is abundant evidence from other studies ${ }^{22}{ }^{23}$ that patients have explanatory models of their symptoms which contain current and outdated biomedical ideas and are "scientific" in the sense that they are both scrutinised critically and subject to empirical test and refutation. ${ }^{24}{ }^{25}$ Our study suggests that despite this shared basis, patients with somatisation disorders perceived the explanations of most doctors as being at odds with their own thinking. The predominant view that emerges is that patients and doctors hold positions that are not merely disparate but in conflict. In patients with somatisation disorders, the conviction that the reality of their symptoms is attested by information that only they can have and its corollary that doctors' information is inevitably limited and fallible are central to the conflict. ${ }^{21}{ }^{26}$ Moreover, patients' understanding of their symptoms involves weighing and scrutinising doctors' explanations along with other sources of information. ${ }^{1122} 27$

Our categorisation of patients' accounts of their doctors' explanations seems to reflect these realities. Most explanations were experienced as a rejection of patients' suffering. They failed to connect with patients' ideas; implied that negative test results equated with absence of cause; or proffered labels that were perceived as stigmatising or indicated that their doctor did not understand, or believe in, the existence of the symptoms. At an intermediate level were explanations reflecting the doctor's acquiescence when patients presented medical explanations for their symptoms. While this collusion was not viewed as rejection, it undermined patients' confidence in the previous openness or even the competence of their doctor. Finally, a few patients recounted explanations that they had assimilated and which seemed to have led to their empowerment. These explanations provided a tangible, usually physical, causal mechanism; they exculpated the patient by attributing symptoms to causes for which the patient could not be blamed; and they involved the patient by invoking internal
Key messages

- Patients with somatisation disorders make disproportionately heavy demands on health services

- Doctors' explanations of their symptoms are often at odds with these patients' own thinking

- Patients with somatisation disorders describe three types of medical explanation-rejecting, colluding, and empowering

- Empowering explanations are tangible, exculpating, and involve patients in managing their illness

- Patients' reactions to empowering explanations suggest that these have the potential to reduce demand for health care

adjustment or suggesting external factor(s) that the patient could influence.

Tangible, physical explanations are consistent with the patients' essentially physical conception of the body and its functions. ${ }^{27}$ The view that a mechanical system provides "a useful metaphor to mediate between patient and doctor" ${ }^{27}$ may have particular relevance to the management of psychosomatic problems by avoiding labels perceived as stigmatising and by "making a link" between physical symptoms and emotional factors. ${ }^{28}$ The empowering format of explanation overlaps with the approach adopted in reattribution and other cognitive therapies. ${ }^{28-30}$ However, these treatments are appropriate and available for only a few patients with somatisation disorders, whereas empowering explanations can form part of any medical consultation. Because patients with somatising disorders impose a disproportionate burden on health services, we suggest that wider use of empowering explanations could benefit them and health services generally. ${ }^{31} 32$

We thank Dr Michael Rose for assistance.

Contributors: PS and IS jointly designed, established, and managed the study from which this work arose. PS initiated the analysis of transcripts, and participated in further analysis, interpretation of results, and writing the paper. IS conceived the aim of this paper, participated in the analysis and interpretation of results, and led the writing of the paper. SP recruited patients, conducted the interviews, and contributed to data analysis and to writing the paper. All three authors act as guarantors.

Funding: Medical Research Council.

Competing interest: None declared.

Beauchamp TL, Childers JF. Principles of biomedical ethics. 4th ed. New York: Oxford University Press, 1994

2 NHS Executive. Patient partnership: building a collaborative strategy. Leeds: NHS Executive, 1996.

3 Simpson M, Buckman R, Stewart M, Maguire P, Lipkin M, Novack D, et al. Doctor-patient communication: the Toronto consensus statement. BMJ 1991;303:1385-7.

4 Audit Commission. What seems to matter: communication between hospitals and patients. London: HMSO, 1993.

5 Kleinman A. Concepts and a model for the comparison of medical systems as cultural systems. Soc Sci Med 1978;12:85-93.

6 Helman CG. Culture, health and illness. 3rd ed. London: ButterworthHeinemann, 1994.

7 Shorter E. From paralysis to fatigue. A history of psychosomatic illness. New York: Free Press, 1992.

8 Craig TKJ, Boardman AP. Somatisation in primary care settings. In: Bass CM, ed. Somatisation: physical symptoms and psychological illness. Oxford: Blackwell, 1990. 
9 Salmon P, May C. Patients' influence on doctors' behaviour: a case study of patient strategies in somatization. Int J Psychiatry Med 1995;25: 309-19.

10 Marchant-Haycox S, Salmon P. Patients' and doctors' strategies in consultations with unexplained symptoms: interactions of gynecologists with women presenting menstrual problems. Psychosomatics 1997;38:440-50.

11 Blaxter M. The causes of disease. Women talking. Soc Sci Med 1989;17:5969.

12 Borkan J, Reis S, Hermoni D, Biderman A. Talking about the pain: a patient-centered study of low back pain in primary care. Soc Sci Med 1995;40:977-88.

13 Helman CG. Psyche, soma and society: the social construction of psychosomatic disorders. Culture Med Psychiatry 1985;9:1-26.

14 Zigmond AS, Snaith RP. The hospital anxiety and depression scale. Acta Psychiatr Scand 1983;67:361-70

15 Dey I. Qualitative data analysis: a user-friendly guide for social scientists. London: Routledge, 1993.

16 Patton MQ. Qualitative evaluation and research methods. 2nd ed. Newbury Park, CA: Sage, 1990.

17 Mays N, Pope C. Rigour and qualitative research. BMJ 1995;311:109-12

18 Stiles WB. Quality control in qualitative research. Clin Psychol Rev 1993;13:593-618

19 Guba EG, Lincoln YS. Fourth generation evaluation. Newbury Park, CA: Sage, 1989.

20 Royal College of General Practitioners, Office of Population Censuses and Surveys, Department of Health. Morbidity statistics from general practice. Fourth national study, 1991-1992. London: HMSO, 1995.

21 Peters S, Stanley I, Rose M, Salmon P. Medically unexplained symptoms: sources of patients' authority and implications for demands on medical care. Soc Sci Med 1998;46:559-63

22 Hunt L, Jordan B, Irwin S. Views of what's wrong: diagnosis and patients perceptions of illness. Soc Sci Med 1989;28:945-56

23 Pill R, Stott N. Concepts of illness causation and responsibility: some preliminary data from a sample of working mothers. Soc Sci Med 1982;16:4352.

24 Shorter E. Sucker-punched again! Physicians meet the disease of the month syndrome. J Psychosom Res 1995;39:115-8.

25 Stimson GV. Obeving doctor's orders: a view from the other side. Soc Sci Med 1974;8:97-104.

26 Toombs SK. The meaning of illness. A phenomenological account of the different perspectives of physician and patient. Dordrecht: Kluwer Academic Publishers, 1993.

27 Mabeck C, Olesen F. Metaphorically transmitted diseases. How do patients embody medical explanations? Fam Pract 1997;14:271-8.

28 Goldberg D, Gask L, O'Dowd T. The treatment of somatisation: teaching the skills of reattribution.J Psychosom Res 1989;33:689-95.

29 Speckens A, van Hemert A, Spinhoven P, Hawton K, Bolk J, Rooijmans H. Cognitive behavioural therapy for medically unexplained symptoms: a randomised controlled trial. BMJ 1995;311:1328-32.

30 Mayou R, Sharpe M. Treating medically unexplained physical symptoms. BMJ 1997;315:561-2.

31 Smith GR. The course of somatization and its effects on the utilization of health care resources. Psychosomatics 1994;35:263-7.

32 Speckens A, van Hemert A, Bolk J, Rooijmans H, Hengeveld M. Unexplained physical symptoms: outcome, utilization of medical care and associated factors. Psychol Med 1996;26:745-52.

(Accepted 20 October 1998)

\section{When I use a word... Homogenous/homogeneous}

Sir Edwin Ray Lankester (1847-1929), having gained first class honours in natural science at Oxford in 1868, returned in 1891 to take the Linacre chair of comparative anatomy, becoming one of the leading zoologists of his generation. Lankester's works are cited a little over 300 times in the Oxford English Dictionary-an impressive tally. For comparison, the major novels of Thomas Hardy, Lankester's almost exact contemporary, are cited about 700 times. But what distinguishes Lankester is his use of neologisms: in two thirds of the citations his is the first recorded use of the word. Sometimes he created a completely new word to describe a new phenomenon or to translate a foreign text; elsewhere he used existing words in new meanings or to derive new adjectives or verbs. The words that he is recorded as having used first include gonad, host (an animal or plant that harbours a parasite), musculature, proctodaeum, toxin, and homogenous.

Lankester introduced "homogenous" in an article in the Annals of Natural History (1870;6:34-43), in which he proposed that there were two different ways in which homology in organisms could arise: homogeny (through common ancestry) and homoplasty (through common environment). The suffix -geny probably originally derived from the triliteral root GEN in $\gamma \varepsilon \dot{\varepsilon} \varepsilon \sigma \iota \varsigma$ (genesis, from $\gamma$ í $\gamma \varepsilon \varepsilon \sigma \theta \alpha$, gignesthai, to be born). The proper adjectival form is therefore -genetic, and indeed the title of Lankester's paper was "On the use of the term Homology in modern Zoology; and the distinction between Homogenetic and Homoplastic agreements." However, in the text he perversely used two different adjectives, homogenous and homogenetic. His reasons for choosing one or the other are not clear, although he tended to use "homogenous" when describing structures that have homogeny, a common genetic origin, and "homogenetic" when qualifying another noun-for example, "homogenetic agreement."

Now take homogeneous, an older word than homogenous (the earliest citation in the $O E D$ comes from Milton). If two things are homogeneous they are congruous, alike in constitution, of uniform nature or character throughout. A population is homogeneous if its members have some common characteristic. A tissue is homogeneous if it is composed of similar cells. In homogeneous equations the sum of the indices in each term is the same-for example, $x^{3}-x^{2} y+x y^{2}-y^{3}=0$. In the Iliad we read (13:354) that Zeus and Poseidon were of the same stock,

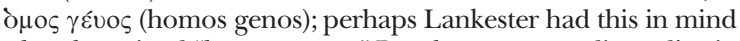
when he coined "homogenous." But the corresponding adjective

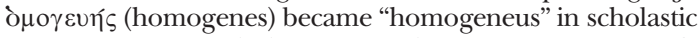
Latin. And in English this became "homogeneous," by conflation of -eus with another suffix, -ous, which came from the Latin suffix -osus, meaning full of, giving the word a different meaning from its Greek roots.

So homogenous and homogeneous have distinct meanings. But homogenous is nowadays virtually always mistakenly used to mean homogeneous. For instance, a Medline search of the titles and abstracts of papers published throughout the world in 1997 shows 170 instances of "homogenous," in almost all cases incorrectly used to mean "homogeneous." In 1348 other papers "homogeneous" was used. In contrast, since 1965 (when the database starts) the British Medical Journal has not used the word homogenous in any title or abstract; the one case in which it appeared to do so $(1975 ; 3: 18-20)$ turned out to be a misprint in Medline!

Homogenous is probably mistaken for homogeneous because the two words look alike and because homogenous is not nowadays commonly used in its original meaning. "Homogenize," which means to make homogeneous, may have exacerbated the confusion.

But don't confound the two. After all, you don't think that knowing all the answers to the questions in the variety of Trivial Pursuit known as "Genus" makes you a genius-do you?

Jeff Aronson, clinical pharmacologist, Oxford

We welcome articles up to 600 words on topics such as A memorable patient, A paper that changed my practice, My most unfortunate mistake, or any other piece conveying instruction, pathos, or humour. If possible the article should be supplied on a disk. Permission is needed from the patient or a relative if an identifiable patient is referred to. We also welcome contributions for "Endpieces," consisting of quotations of up to 80 words (but most are considerably shorter) from any source, ancient or modern, which have appealed to the reader. 